\title{
Automating and Informating: Roles to Examine in Technology's Impact on Performance
}

\begin{abstract}
Information quality and system quality are considered key factors in determining the usefulness of systems. However, prior studies have yielded mixed results. This article holds that the system's assistance (the degree of the assistance provided by a system through its two roles: automating and informating) mediates in this relationship and may help to explain such mixed results. Furthermore, it holds that the system's level of intervention (the degree to which technology participates in carrying out the tasks) is another key factor in determining its usefulness, especially through the automating role. Data from 246 users filling different hierarchies and functional areas were collected. Results show that information quality and system's level of intervention explain usefulness through both roles. System quality explains usefulness through the informating role, but not through the automating role. The factors' differentiated effects through each role may help managers to establish more effective criteria and priorities in the different stages of an information system's life cycle.
\end{abstract}

Keywords: Information systems, usefulness, roles, information quality, system quality, automating

\section{INTRODUCTION}

A main objective in the field of information systems is the study between technology and its impact on performance (Downey, 2004; Petter, DeLone, \& McLean, 2012). Though this relationship has been widely studied, empirical evidence shows that the benefits of information systems are often fewer than expected, or they do not entirely materialize (Fadel, 2012).

Research on technology's impact on individual performance-most of the times operationalized as usefulness (Petter, DeLone, \& McLean, 2008) -proposes a direct relationship between «technological factors» (system quality and information quality) and usefulness (Seddon, 1997). DeLone and McLean (2003) also refer to the direct relationships between these factors and usefulness. Etezadi-Amoli and Farhoomand (1996) empirically show a positive relationship among these variables. These models are still used and studied (Urbach \& Muller, 2012). However, the empirical research that examines such direct link has produced mixed results (Petter et al., 2008). Some authors have found a positive relationship between system quality (in its ease-of-use dimension) and usefulness (Rai, Lang, \& Welker, 2002; Seddon \& Kiew, 1997; Thompson, Compeau, \& Higgins, 2006) whereas others have found the relationship between them is not significant (Chau \& $\mathrm{Hu}, 2002$; Wu \& Wang, 2006). For example, Chau and $\mathrm{Hu}$ (2002), in their study on telemedicine systems, suggest that physicians are not likely to consider a technology to be useful simply because it is easy to use. Moreover, some authors have found a positive relationship between information quality and usefulness (Kositanurit, Ngwenyama, \& Osei-Bryson, 2006; Rai et al., 2002), while others have found a non-significant relationship between them. For instance, in the context of a knowledge management system, Kulkarni, Ravindran, and Freeze (2007) attribute that nonsignificance to the fact that those systems are in an incipient stage, and the information stored in them does not yet help individuals to perform specific tasks. 
Adams, Nelson, and Todd (1992) found a similar problem-i.e., mixed results-when exploring the relationship between ease-of-use and system use. They proposed to include variables that could mediate such link. Such is also the focus of this article where we explore if the system's assistance, in its different roles, mediates the link between technological factors and usefulness.

Zuboff (1985) points out that a system may provide assistance through two roles, namely «automating» and «informating». Through automating, the system replaces humans in performing tasks; by informating, the system helps organizing, summarizing and analyzing information. Likewise, Mooney, Gurbaxani, and Kraemer (1996) argue that technology improves performance through the effects of these roles. Alter (1999) suggests that a system has an impact to the extent its capacities -i.e., technological factors- allow performing such roles appropriately. This literature suggests that the degree of system's assistance-in both roles-may mediate the link between technological factors and usefulness.

The automating and informating effects have been used as mediating variables between the system's capacities and performance although at the processes or organizational level (Karimi, Somers, \& Bhattacherjee, 2007; Uwizeyemungu \& Raymond, 2012). Less attention has been paid to the effect of these roles on the relationship between technological factors and usefulness at the individual level.

In addition, different models of technology's impact (DeLone \& McLean, 1992; Seddon, 1997) have identified information quality and system quality as antecedents of usefulness. A possible explanation is that these models come from the theory of communication (Mason, 1978) which conceives the information system as a process to produce information, where the system quality reflects the desired internal characteristics of the process and the information quality reflects the desired characteristics of the outcome -information-(DeLone \& McLean, 1992). But, following Alter (1999, p. 30): "Contrary to the common assumption that a typical information system's purpose is to provide information to work system participants, information systems may serve work systems in a variety of roles."

One of these roles is automation, which has to do with performing activities that replace human labor, instead of producing information. Such replacement results from an organizational decision that determines which activities shall be carried out by individuals and which by technology (Kaber \& Draper, 2004). The more activities assigned to technology, the greater the automation. None of the factors-system quality or information quality-present in the abovementioned models reflects such assignment. To that extent, it is necessary to explore the effect produced by the system's level of intervention in its usefulness.

Within this framework, this article aims at studying the relationship among technological factors (system quality, information quality and system's level of intervention), system's assistance (in the automating and informating roles) and usefulness. This article proposes (1) that system's assistance mediates the relationship between technological factors and usefulness, and (2) that it is necessary to include the system's level of intervention since it helps explain usefulness, especially through the automating role.

This article makes two contributions. First, it expands on the existing literature by proposing, and empirically testing, the relationship among technological factors, system's assistance and usefulness. Second, it helps managers by showing that a factor's relevance varies depending on the role played by the system. This should help them in making decisions about the design, building, and assessment of a system. 
In its first section, this article develops the model and $\mathrm{p}$ roposes several hypotheses linking technological factors, system assistance and usefulness. Next, it presents the methodology. The subsequent section presents and discusses the results of the study. The article ends with a section on contributions, limitations, implications for management and some ideas for further research.

\section{RESEARCH MODEL}

\section{System's Assistance and Usefulness}

Usefulness, in the literature on technology impact, is defined as the extent to which individuals consider technology has improved their performance (Seddon, 1997). In turn, improved performance means the individual is more efficient and/or effective (Goodhue \& Thompson, 1995).

An information system may play different roles in this regard. Zuboff (1985) argues that technology may be applied in two scopes. The first is the automating of operations to replace human effort and abilities with technology capable of performing certain tasks at a lower cost, while providing better control and continuity. The second one refers to creating information (informating), which takes place when -simultaneously, as part of the automating processinformation on the business activities is produced. Such information is stored, organized, summarized and analyzed for several activities within the organization. Alter (1999) explains an information system performs several roles, most notably providing information and automating activities. Thus, an information system provides information when the individual uses it to analyze a specific issue or to monitor the progress of an activity. And a system automates activities when it releases the individual from performing tasks that support a process.

To sum up, in this article, «role» is the way in which an information system assists the individuals when performing their tasks. For the automating role, the system carries out activities replacing the individual, whose intervention is minimal (e.g., when the system processes payment transaction to suppliers). For the informating role, the system allows accessing, processing and analyzing the information (e.g., when the system helps analyzing the clients' payment history). Since this research studies the effects produced by these roles on performance, it is necessary to define «system's assistance in the automating role» and «system's assistance in the informating role» as the degree to which technology helps the individual in each corresponding role.

In general, several authors suggest a relationship between system's assistance and technology's impact on performance (usefulness). Alter (1999) states that the system's impact on performance is mainly determined by the extent to which the information system plays its roles effectively. Mooney et al. (1996) refer that technology has separate yet complementary effects on tasks. In the automating role, the system produces effects when substituting labor for technology assets; and in the informating role, technology has effects emerging from the system's capacities for collecting, storing, processing and disseminating information. These authors add that it is through these effects that performance will be enhanced. In the empirical field, McMahan, Woodman, and Wright (1995), through an experiment where individuals have to assess candidates for scholarships, found that both under automating and informating situations, stronger performance is achieved than without technology.

Specifically, system's assistance in the automating role has effects on usefulness, since technology may allow carrying out activities more efficiently and effectively than with the 
manual alternative. Radhakrishnan, $\mathrm{Zu}$, and Grover (2008) indicate that the system, under this role, improves the ability to produce in larger amounts and with higher quality, by increasing the processing capacity and reducing flaws or losses. The system can also reduce processing time (Merchant, 2000), improve accuracy, reduce response time to clients and help with complex and routine calculations (Yi, Purao, Clark, \& Raghuram, 2009).

Furthermore, system's assistance in the informating role has effects on usefulness, because individuals are able to access and handle information, which allows them to carry out several activities more efficiently and effectively. Radhakrishnan et al. (2008) argue that the system, under this role, has positive effects because technology is capable of storing, retrieving, handling and disseminating information, enabling better activity planning and control, and thus enhancing performance. The system can also provide information allowing the individual to identify problems and determine courses of action (Schein, 1994), forecast demand and identify potential markets (Anderson, Banker, \& Hu, 2003) or analyze clients and competitors (Boujena, Johnston, \& Merunka, 2009).

The following hypotheses are established on these grounds:

H1: The greater the system's assistance in the informating role, the more useful it will be.

$\mathrm{H} 2$ : The greater the system's assistance in the automating role, the more useful it will be.

\section{Information Quality, System Quality and System's Assistance}

System quality is referred to as system reliability (free of flaws), ease of use, and document quality, among others. Similar to Seddon and Kiew (1997) and Rai et al. (2002), in this article, system quality refers strictly to ease of use. Information quality means the relevance, timeliness and accuracy of the information generated by the system (McGill, 2004; Seddon, 1997).

In general, several authors suggest a relationship between such technological factors (system quality and information quality) and system's assistance under both roles. Alter (1999) indicates that a system has an impact in as far as its capabilities (i.e., technological factors) allow it to provide information (informating role) or to actively participate in the business processes (automating role). Goodhue (1998) points out that an information system supports information identification, data access and information interpretation, activities similar to the informating role, and adds that such activities need a system with different associated factors. For instance, for the identification activity, information should have an appropriate level of detail (information quality); or for the interpretation activity, information should be accurate (information quality); or for the access activity, the system should be easy to use and flexible (system quality). Therefore, these technological factors would determine to what extent the automating and informating roles are met.

Specifically, in the informating role, the system allows the individual to analyze or handle information, and for that it needs information quality. For instance, if a person has the task to detect those clients representing an above-average risk of defaulting on their payments, his/her analysis should be based on accurate information. Moreover, in the automating role, even though the system does not necessarily present the information to the user, it also internally needs information quality. For example, poor quality information would negatively affect the automation of a payment processing task.

On these grounds we may establish: 
H3: The better the information quality, the greater the system's assistance in the informating role.

H4: The better the information quality, the greater the system's assistance in the automating role.

In addition, in the informating role, the individual should interact with the system to be able to retrieve, analyze and handle the information. Such interaction will be favored if the system is easy to use (simple, user-friendly, easy to operate). Furthermore, though in the automating role by definition there is less human intervention, the individual needs a friendly and easy interface for basic operations, such as starting the transaction and/or viewing results.

On these grounds we may establish:

H5: The better the system quality, the greater the system's assistance in the informating role.

H6: The better the system quality, the greater the system's assistance in the automating role.

\section{System's Level of Intervention and System's Assistance}

In the automation literature, Kaber and Draper (2004) state that the activities of an individual may be carried out within a range from completely in charge of the person -i.e., without technology's intervention- to completely done by technology -i.e., completely automated. Endsley and Kaber (1999) developed a taxonomy for levels of intervention, incorporating ten levels (ranging from manual control to full automation) based on a mixed allocation of functions, either to the person or to the system (functions such as information monitoring, generation of action alternatives and alternative implementations). Moreover, Parasuraman, Sheridan, and Wickens (2000) propose different levels of technology intervention, through different functions related to task performance (collecting information, analyzing information, selecting the decision and implementing the decision). In systems literature, Alter (1999) acknowledges that an information system may have different levels of integration with the tasks it serves. At a minimal level of integration, tasks and technology are separate entities (e.g., the system only provides information to carry out the tasks). At a higher level of integration, the system becomes a tool or an active component for the tasks (e.g., an automatic bill payment system). In such a context, the system's level of intervention is defined by the degree to which technology participates in carrying out the individual's tasks.

The system's level of intervention may influence the system's assistance based on the relative advantage of technology. Price (1985) outlines a range from a point where technology has a better performance than the human, to another one where humans perform better than technology. Hoffman, Feltovich, Ford, and Woods (2002) refer to activities where technology beats humans, for instance at managing complex operations and in deductive reasoning, while humans beat technology, for example in exercising judgment or inductive reasoning. Saridis (2000) holds that reliability, continuity, accuracy and independence of human fatigue are advantages of technology. Empirical studies in the automation field show that a higher level of technology intervention is related to an enhanced performance (Endsley \& Kaber, 1999; Wei, Macwan, \& Wieringa, 1998).

In that framework, organizations are expected to design the work of individuals by assigning a specific level of participation to technology for performing tasks. That assignment would be made inasmuch as the technology offers a relative advantage. Following this reasoning, it is possible to argue that a higher system's level of intervention would allow increasing the system's level of assistance. 
Specifically, as the system's level of intervention increases, it would be expected the system would assume a larger part of the activities, especially routine activities. Therefore, the individual would consider that the system is assisting him/her in the automating role.

Moreover, as the system's level of intervention increases, it is expected that data retrieving, information analysis or information handling would be better supported by the system. Thus, the individual would consider that the system is assisting him/her in the informating role.

On these grounds we may state that:

H7: The higher the system's level of intervention, the greater the system's assistance in the informating role.

H8: The higher the system's level of intervention, the greater the system's assistance in the automating role.

Figure 1 summarizes the research model.

Figure 1. Research model

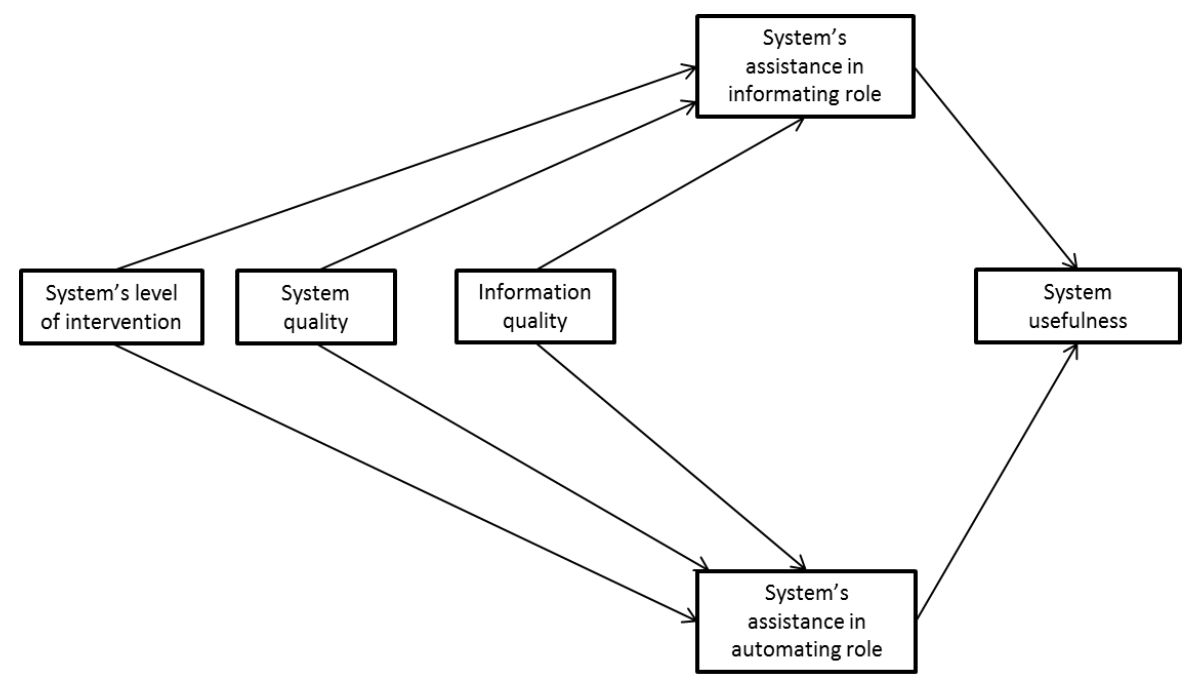




\section{METHODOLOGY}

To test the proposed hypotheses, we conducted a field study, using a questionnaire as the data collection instrument and the structural equations model for the analysis. To establish the model's degree of generalization, we considered three aspects of domain in which this study will be conducted: (1) the information system is an Enterprise Resources Planning System (ERP); (2) the tasks will be those business activities that the individual fully or partially performs using the information system; and (3) the individual shall be anyone using an information system to perform tasks regardless of his/her hierarchy (operational or management), functional area or business sector. The individual must have used the information system for at least three months.

The questionnaire is principally based on previously used scales, which are adjusted to the study context in accordance with the abovementioned domain. A common feature of the scales is that they can be used transversally in any type of task or system considered in the study domain. These scales consider mostly items that have been broadly used in the literature. The scale developed by Seddon and Kiew (1997) has been used as a base to measure usefulness, adding an item used by Stone, Good, and Baker-Eveleth (2007). To measure system quality from the standpoint of its ease-of-use dimension, we used the scale prepared by Seddon and Kiew (1997), adding items used by Etezadi-Amoli and Farhoomand (1996), as well as Venkatesh and Davis (2000). Measurement of information quality was based on a scale developed by Kositanurit et al. (2006). The scale developed by Muhammed (2007) was used to measure the system's assistance in the automation role. Measurement of the system's assistance in the informating role was based on items derived from information processing activities indicated by Zuboff (1985), and Goodhue, Littlefield, and Straub (1997). Measurement of the level of intervention was adapted from the scale developed by Muhammed (2007). The 28 items used in the final study are listed in the Annex.

Considering that we worked with a Spanish-speaking population and to assure a reliable translation, we used the back-translation technique (Brislin \& Freimanis, 1995). Several studies in the field have used the same technique (e.g., Sun, Bhattacherjee, \& Ma, 2009). The final questionnaire design asks the participant to: (1) indicate the information system he/she uses more frequently and the tasks he/she carries out, fully or partially, assisted by such system; (2) indicate his/her degree of agreement - disagreement with aspects referred to the information system and the tasks mentioned above; and (3) indicate the system's frequency of use and demographic data. For the questions referring to the system and the tasks, we used Likert (seven points) scales, from "1" totally disagree to "7" totally agree.

The scales were subject to several preliminary tests to assure their validity. In a pre-test we interviewed a group of users of an information system to detect potential problems of understanding. Then, a pilot test was conducted, under the same conditions and with the same type of participants as the final questionnaire. The result of each one of these activities led to successive improvements on the questionnaire.

During the data collection stage, the questionnaires were distributed among graduate professionals who were working for companies in Peru, and simultaneously attending different training programs in a well-known Peruvian university. The participants were asked to fill the questionnaire voluntarily. Several previous field surveys have followed a similar procedure (e.g., Gefen, Karahanna, \& Straub, 2003). Data were compiled in July and August 2012 after distributing 320 questionnaires. After discarding blank and incomplete questionnaires, or those that did not belong in the specified domain, 246 questionnaires were left. 
Individuals came mostly from the Finance (30\%), Logistics (32\%) and Marketing (7\%) areas, and they belonged to operational (51\%), supervisor (33\%) and management (16\%) levels; 93\% of individuals came from private companies, and the balance from government.

Respondents used an information system 21 hours a week on average, and had used it for an average 40 months. Systems included SAP (27\%) and Oracle (15\%). The tasks reported by the participants correspond to typical activities of the business process in their corresponding areas (e.g. warehouse management, purchase management, billing).

\section{RESULTS}

Table 1 shows the average and the standard deviation for the constructs. These were calculated by previously averaging out the responses on the items for each scale.

Table 1. Descriptive Statistics

\begin{tabular}{|l|r|r|}
\hline Construct & \multicolumn{1}{|l|}{ Mean } & $\begin{array}{c}\text { Standard } \\
\text { Deviation }\end{array}$ \\
\hline Information quality (IQ) & 5.15 & 1.07 \\
\hline System quality (SQ) & 5.27 & 1.07 \\
\hline System's level of intervention (SLI) & 5.09 & 1.16 \\
\hline System's assistance in informating role (SAI) & 5.02 & 1.07 \\
\hline System's assistance in automating role (SAA) & 4.93 & 1.15 \\
\hline System usefulness (SU) & 5.14 & 1.09 \\
\hline
\end{tabular}

To analyze the data, this research uses structural equations that allow modeling relationships among multiple independent and dependent constructs simultaneously, as well as analyzing relations among latent variables with multiple indicators. We used IBM's SPSS AMOS 20 software. Data were analyzed in two stages. First, we developed and assessed the measurement model and secondly, we assessed the structural model.

\section{Measurement Model}

We ran a Confirmatory Factor Analysis (CFA). The measurement model is estimated with the maximum likelihood method and the covariance matrix. Table 2 presents the correlations, variance extracted and reliability, all calculated based on the data and AMOS estimations.

Table 2. Correlations, reliability and average variance extracted (AVE)

\begin{tabular}{|c|c|c|c|c|c|c|c|c|}
\hline \multirow[t]{2}{*}{ Construct } & \multicolumn{6}{|c|}{ Correlations and square root of AVE $\left({ }^{*}\right)$} & \multirow{2}{*}{$\begin{array}{l}\text { Cronbach's } \\
\alpha\end{array}$} & \multirow[t]{2}{*}{ AVE } \\
\hline & SU & SAA & SAI & SQ & IQ & SLI & & \\
\hline SU & 0,898 & & & & & & 0,948 & 0,806 \\
\hline SAA & 0,747 & 0,886 & & & & & 0,947 & 0,785 \\
\hline SAI & 0,824 & 0,710 & 0,854 & & & & 0,914 & 0,729 \\
\hline SQ & 0,573 & 0,549 & 0,643 & 0,884 & & & 0,946 & 0,782 \\
\hline IQ & 0,728 & 0,659 & 0,717 & 0,609 & 0,808 & & 0,908 & 0,653 \\
\hline SLI & 0,773 & 0,711 & 0,688 & 0,565 & 0,645 & 0,844 & 0,930 & 0,713 \\
\hline
\end{tabular}

Note (*): Diagonal numbers are the square root of AVE for each construct and off-diagonal numbers are the correlations between constructs.

Reliability assessed through Cronbach- $\alpha$ shows acceptable values over 0.7. Convergent validity is verified since all the standardized factor loadings are significant and higher or 
equal to 0.7. Discriminant validity is verified since the correlation between a pair of latent variables is less than the square root of variance extracted of the variable (see Table 2).

Afterwards, the measurement model's fit is assessed, resulting in the indicators shown in Table 3. The values are acceptable and in line with the values recommended in the literature (Gefen, Straub, \& Boudreau, 2000; Hair, Black, Babin, Anderson, \& Tatham, 2006).

Table 3. Fit indicators for the measurement model

\begin{tabular}{|l|l|l|}
\hline Indicator & $\begin{array}{l}\text { Recommended } \\
\text { values }\end{array}$ & $\begin{array}{l}\text { CFA model } \\
\text { values }\end{array}$ \\
\hline$\chi^{2}$ ratio & $<3$ & 1.682 \\
\hline CFI & $>0.9$ & 0.967 \\
\hline TLI & $>0.9$ & 0.963 \\
\hline SRMR & $<0.08$ & 0.040 \\
\hline RMSEA & $<0.08$ & 0.053 \\
\hline
\end{tabular}

\section{Structural Model}

In view of the satisfactory findings reached in the CFA analysis, in the second stage we assessed the structural model. First of all, the model's fit assessment yielded an acceptable adjustment for all indicators (Table 4).

Table 4. Fit indicators for the structural model

\begin{tabular}{|l|l|l|}
\hline Indicator & $\begin{array}{l}\text { Recommended } \\
\text { values }\end{array}$ & $\begin{array}{l}\text { Structural model } \\
\text { values }\end{array}$ \\
\hline$\chi^{2}$ ratio & $<3$ & 1.782 \\
\hline CFI & $>0.9$ & 0.962 \\
\hline TLI & $>0.9$ & 0.958 \\
\hline SRMR & $<0.08$ & 0.046 \\
\hline RMSEA & $<0.08$ & 0.057 \\
\hline
\end{tabular}

Figure 2 shows the standardized coefficient and the significance of the links, as well as the variance explained from latent variables. The links are significant to the 0.001 level, except for the link between system quality and system assistance in the automating role, which was not found to be significant. Furthermore, $75 \%$ of usefulness variance is explained. Likewise, the three factors explain $67 \%$ of the system's assistance in the informating role variance and $60 \%$ of system's assistance in the automating role variance. 


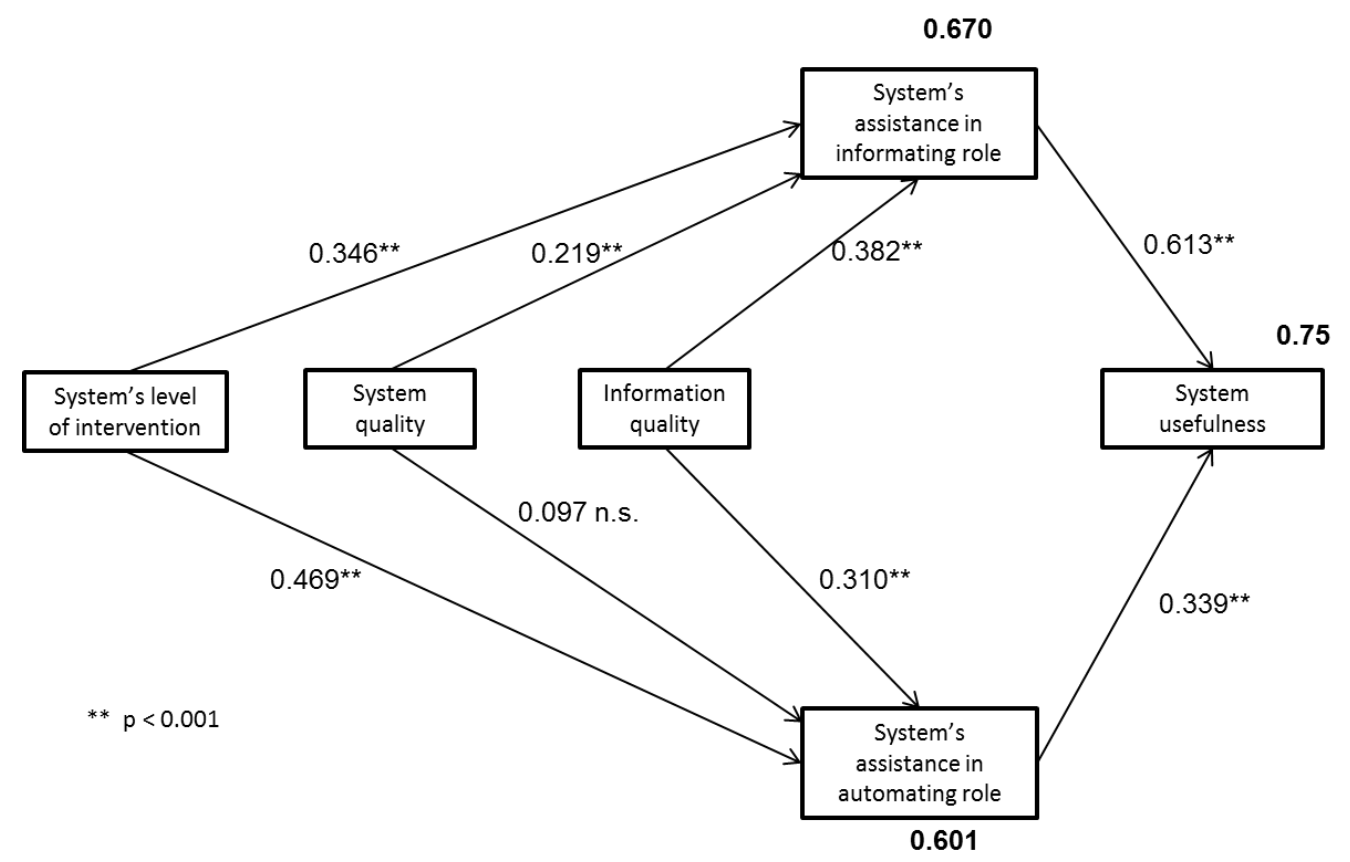

\section{DISCUSSION}

The study's main finding shows empirically that system's assistance in both roles mediates in the relationship between technological factors (system's level of intervention, system quality and information quality) and usefulness. Besides, this mediation can explain the differential effects of technological factors on usefulness.

Specifically, results show that usefulness depends on the system's assistance in both roles (hypotheses H1, H2). This suggests that the assessment of usefulness will be higher to the extent the system helps automating tasks or analyzing information. Prior theoretical studies proposed that a system has differentiated-though complementary-effects through both roles (Alter, 1999; Mooney et al., 1996) and in their experiment McMahan et al. (1995) identified such effects separately for each role. Our study confirms these propositions and findings.

The study reveals that information quality explains the system's assistance in both roles (hypotheses H3, H4). This suggests that, when the system provides timely, clear and updated information, the individual may able to analyze data (informating role) and/or process transactions (automating role) in a more accurate and timely manner. This will lead to positively value the system's level of assistance in both roles. Prior theoretical studies suggested that technology factors influence the fulfillment of both roles (Alter, 1999; Goodhue, 1998). Our investigation empirically confirms such proposition, and it also shows that information quality is relevant for both roles.

The results show that system quality explains the system's assistance in the informating role (hypothesis H5), but not in the automating role (hypothesis H6). This suggests that in the informating role, where a larger man-machine interaction is expected, a simple and understandable interface may increase speed of, and reduce mistakes in, task execution. This would lead to positively value the level of assistance in that role. On the other hand, there are possible explanations for rejecting hypothesis H6. Firstly, in the automating role, by 
definition, the system carries out the task with a minimum participation of the individual. This minimum interaction would lead to value the system quality (in its ease-of-use dimension) less significantly than others factors. Secondly, the tasks that are usually automated are the ones that are more routinized. Therefore, since in those cases the employee uses the interface regularly, the individual may have learned or generated automated mechanisms for using it. In that sense, system quality (easiness) becomes irrelevant when assessing its impact in the automating role.

The study also reveals that the system's level of intervention explains the system's assistance in both roles (hypotheses H7 and H8). This suggests that if the system intervenes more deeply in the activities, the individual may process transactions (automating role) or analyze information (informating role) more quickly and reliably. This will lead to a positive assessment of the level of system's assistance in both roles. Prior research found evidence showing that the system's level of intervention has an impact on performance (Endsley \& Kaber, 1999; Wei et al., 1998). Our study is in line with such results; however, unlike those studies, we used the system's assistance as an intermediate variable.

In examining the relative importance of the three antecedents of assistance in the informating role, we find that information quality has a larger impact, as shown by the standardized corresponding coefficients (information quality $=0.382$, system's level of intervention $=$ 0.346 and system quality $=0.219$ ). This result is not surprising since, due to the nature of this role, accurate and updated information will carry a heavier weight on information analysis. Moreover, observing the relative significance of the assistance factors in the automating role, we find that the system's level of intervention has the largest impact in accordance with the standardized coefficient (system's level of intervention $=0.469$, information quality $=$ 0.31 and system quality $=0.097$ n.s.). This is also an expected result, since due to the nature of this role, a more active participation of technology will have more weight on routine or automatable activities.

Finally, the study shows that system's assistance in the informating role (standardized coefficient $=0.613$ ) has a higher relative significance than system's assistance in the automating role (0.339). This suggests that, to a larger extent, the individual links technology usefulness to informating role tasks. However, it is necessary to research if this association can change depending on the individual's activity mix within each role.

The study as a whole, that is, incorporating the roles and system's level of intervention, provides a more detailed vision of the link between factors and usefulness, which may help putting forth alternative explanations to previous mixed results. For instance, in the relationship between system quality and usefulness, if the system supports only routine activities (automating role), probably the link would not be significant, but if the system provides ad-hoc support to certain activities with a high interface interaction, the link may be significant.

\section{CONCLUSIONS}

This paper has explored how the level of assistance of a system through its automating and informating roles mediates the relationship between technological factors and the system's usefulness. On one hand, the factors' effects on usefulness are mediated by the different roles played by an information system, which is in line with previous theoretical propositions 
(Alter, 1999). This article finds evidence showing that the level of assistance in both roles has an impact on usefulness, which is consistent with previous research (McMahan et al., 1995). It also finds that the system's quality only affects usefulness through the informating role. The non-significant link through the automating role is attributed to the reduced interaction of the individual with the interface of the system in this role. Besides, our study shows that technology's level of intervention, to which the literature has paid little attention, is a significant factor for usefulness through both roles. On the other hand, the factors have a differentiated impact through the roles. Information quality has a larger effect through the informating role and the level of intervention has a larger effect through the automating role, which is consistent with the nature of both roles.

The contributions of these results to the literature are as follows. First, this study (by incorporating the roles) enhances our understanding of the mechanisms that explain the impact of technological factors on usefulness. This model, unlike a model based on direct relationships, provides insights on why some relations are significant but not others, or the reasons behind the relative relevance of each factor. Second, this paper integrates literature that so far has addressed factors, the roles of technology, and usefulness separately. The literature suggests that a system plays different roles, that such roles have an impact on usefulness, and that the factors have an impact on the roles. The present paper articulates the literature in a model that explicitly shows such links. Third, our proposal goes beyond the base contributions nurturing it. Thus, the literature focuses on the information quality and system quality factors; but, within a work environment in which technology plays an increasingly relevant role, the model finds that the system's level of intervention in the individual's tasks is a relevant factor. Fourth, the study clearly shows again what seems to have been set aside by the usefulness models, i.e., that the system is used not only to provide information (informating role) but also provides assistance by replacing the individual in carrying out his/her tasks (automating role).

This study has also implications for practitioners. First, it shows that an information system generates value (has an impact on performance) through two clearly differentiated, yet complementary, roles. To that extent, management's decisions on designing and building information systems should set objectives for, and invest in, both aspects. It is worth mentioning that management is usually aware that a system has to provide information since it is an essential element for its administrative duties, but sometimes it is not equally aware that its operational workers need the system to automate tedious or routine activities. Second, the study indicates that the design, building and certification strategies of a system should be differentiated considering the role in which individuals will use the system. The design stage may determine which modules are more oriented towards information handling (informating) and which towards transaction processing (automating), and based on that, different mixes (emphasis on factors) can be established. For instance, if a module is more oriented towards transaction processing, investing in a friendly interface should not be a priority. During the certification stage, the study may lead to establish differentiated criteria to classify the problems found. Two categories may be established in the certification: problems that mandatorily have to be solved or problems recommended to be solved. If the problem is related to an interface problem in a transaction processing option, it could be classified as recommendable. But if the problem is in an information analysis option, it could be classified as mandatory. Third, the study suggests that the assessment stage may proceed in two stages to allow for better targeted corrections. During the first stage, I would review how each role contributes to usefulness, and during the second stage, I would investigate how each factor contributes to the role. For example, if I find low usefulness then I investigate what is each 
role's contribution. If I discover that there is low assistance in the automating role, then I can decide on corrective actions focused on the most relevant factors. Fourth, the study suggests that the optimization of the man-machine pair, by assigning activities to one or the other, should be a main aspect of the design. Technology advances progressively allow for activities that used to be exclusive of the individual to be performed by computers. In such a context, present management decisions can be made within a wider range of automation levels.

Some limitations of this study must be acknowledged. First, data were collected through a sectional survey, which does not provide final evidence on causal relationships. Though the hypotheses are derived from theoretical grounds, longitudinal studies are required to establish causality through the constructs' precedence. Second, the individuals were contacted in the premises of a university, in a similar way to other studies in the field (Gefen et al., 2003). Since these individuals are typical information systems' users, the results may be generalized to a larger extent. It is estimated that individuals were representative subjects (professionals currently employed) and that they were conducting real activities-not simulated ones-(users of a system to do their job), which adds to the level of generalization. Third, all constructs have been measured in a single time point, and with a single questionnaire, which can bias the common method.

Finally, we propose some lines for further research. First, the study refers that the level of interaction with the system that may explain why the system's quality has in impact on usefulness through the informating role, and not through the automating role. An investigation could subject the system and the individual to different levels of interaction and explore in detail such effects. Second, the study also refers that generating automated mechanisms for using the system interface may explain the non-significance of the relationship between system quality and usefulness. A future longitudinal study may review the evolution of this effect. Third, the study suggest that the activities' composition (e.g., information handling vs. routine activities) may determine the relative significance of each role. Their study in different combinations could investigate this behavior in detail. Fourth, the literature acknowledges that technology helps automating and informating but it also allows communicating and accumulating knowledge. Similarly to this article, a study could investigate the mediating effects of the latter roles on usefulness.

\section{REFERENCES}

Adams, D. A., Nelson, R. R., \& Todd, P. A. (1992). Perceived usefulness, ease of use, and usage of information technology: a replication. MIS Quarterly, 16(2), 227-247.

Alter, S. (1999). A general, yet useful theory of information systems. Communications of the Association for Information Systems, 1, 1-69.

Anderson, M., Banker, R. D., \& Hu, N. (2003). The impact of information technology spending on future performance. Paper presented at the The 24th International Conference on Information Systems, Seattle, US.

Boujena, O., Johnston, W. J., \& Merunka, D. R. (2009). The benefits of sales force automation: A customer's perspective. Journal of Personal Selling and Sales Management, 29(2), 137-150.

Brislin, R. W., \& Freimanis, C. (1995). Back-Translation: A tool for cross-cultural research. In C. Sin-wai \& D. E. Pollar (Eds.), An Encyclopaedia of Translation: Chinese-English, English-Chinese (Vol. 1, pp. 22-40). Hong Kong, CN: The Chinese University Press.

Chau, P. Y. K., \& Hu, P. J. (2002). Examining a model of information technology acceptance by individual professionals: An exploratory study. Journal of Management Information Systems, 18(4), 191-229. 
DeLone, W. H., \& McLean, E. R. (1992). Information systems success: The quest for the dependent variable. Information Systems Research, 3(1), 60-95.

DeLone, W. H., \& McLean, E. R. (2003). The DeLone and McLean model of information systems success: A ten-year update. Journal of Management Information Systems, 19(4), 9-30.

Downey, J. P. (2004). Toward a comprehensive framework: EUC research issues and trends (19992000). Journal of Organizational and End User Computing, 16(4), 1-16.

Endsley, M. R., \& Kaber, D. B. (1999). Level of automation effects on performance, situation awareness and workload in a dynamic control task. Ergonomics, 42(3), 462-492.

Etezadi-Amoli, J., \& Farhoomand, A. F. (1996). A structural model of end user computing satisfaction and user performance. Information \& Management, 30(2), 65-73.

Fadel, K. J. (2012). User adaptation and infusion of information systems. Journal of Computer Information Systems, 52(3), 1-10.

Gefen, D., Karahanna, E., \& Straub, D. W. (2003). Trust and TAM in online shopping: An integrated model. MIS Quarterly, 27(1), 51-90.

Gefen, D., Straub, D. W., \& Boudreau, M.-C. (2000). Structural equation modeling and regression: Guidelines for research practice. Communications of the Association for Information Systems, 4, 1-76.

Goodhue, D. (1998). Development and measurement validity of a task technology fit instrument for user evaluations of information system. Decision Sciences, 29(1), 105-138.

Goodhue, D., Littlefield, R., \& Straub, D. W. (1997). The measurement of the impacts of the IIC on the end-users: The survey. Journal of the American Society for Information Science, 48(5), 454465.

Goodhue, D., \& Thompson, R. L. (1995). Task-technology fit and individual performance. MIS Quarterly, 19(2), 213-236.

Hair, J. F., Black, W. C., Babin, B. J., Anderson, R. E., \& Tatham, R. L. (2006). Multivariate data analysis (6th ed.). New Jersey, US: Prentice-Hall.

Hoffman, R. R., Feltovich, P. J., Ford, K. M., \& Woods, D. D. (2002). A rose by any other name... would probably be given an acronym. Intelligent Systems IEEE, 17(4), 72-80.

Kaber, D. B., \& Draper, J. V. (2004). Human-machine system design and information processing. In K. B. Zandin (Ed.), Maynard's Industrial Engineering Handbook (5th ed., pp. 111-137). New York, US: McGraw-Hill.

Karimi, J., Somers, T. M., \& Bhattacherjee, A. (2007). The role of information systems resources in ERP capability building and business process outcomes. Journal of Management Information Systems, 24(2), 221-260.

Kositanurit, B., Ngwenyama, O., \& Osei-Bryson, K.-M. (2006). An exploration of factors that impact individual performance in an ERP environment: an analysis using multiple analytical techniques. European Journal of Information Systems, 15(6), 556-568.

Kulkarni, U. R., Ravindran, S., \& Freeze, R. (2007). A knowledge management success model: Theoretical development and empirical validation. Journal of Management Information Systems, 23(3), 309-347.

Mason, R. O. (1978). Measuring information output: A communication systems approach. Information \& Management, 1(4), 219-234.

McGill, T. (2004). The effect of end user development on end user success. Journal of Organizational and End User Computing, 16(1), 41-58.

McMahan, G. C., Woodman, R. W., \& Wright, P. M. (1995). Automate or Informate? An investigation of the effects on motivation and perfomance (Vol. G 95-7-283). Los Angeles, US: Marshall School of Business, University of Southern California, Center for Effective Organizations.

Merchant, M. E. (2000). The future of manufacturing. In R. L. Shell \& E. L. Hall (Eds.), Handbook of Industrial Automation (pp. 451-455). New York, US: Marcel Dekker.

Mooney, J. G., Gurbaxani, V., \& Kraemer, K. L. (1996). A process oriented framework for assessing the business value of information technology. The Database for Advances in Information Systems, 27(2), 68-81. 
Muhammed, S. (2007). Antecedents and impacts of knowledge management practices supported by information technology: An empirical study in manufacturing context. Doctoral dissertation, The University of Toledo, Toledo, US.

Mukhopadhyay, T., Lerch, F. J., \& Mangal, V. (1997). Assessing the impact of information technology on labor productivity: A field study. Decision Support Systems, 19(2), 109-122.

Parasuraman, R., Sheridan, T. B., \& Wickens, C. D. (2000). A model for types and levels of human interaction with automation. IEEE Transactions on Systems, Man and Cybernetics - Part A: Systems and Humans, 30(3), 286-297.

Petter, S., DeLone, W. H., \& McLean, E. R. (2008). Measuring information systems success: Models, dimensions, measures, and interrelationships. European Journal of Information Systems, 17(3), 236-263.

Petter, S., DeLone, W. H., \& McLean, E. R. (2012). The past, present, and future of IS success. Journal of the Association for Information Systems, 13(5), 341-362.

Price, H. E. (1985). The allocation of functions in systems. Human Factors: The Journal of the Human Factors and Ergonomics Society, 27(1), 33-45.

Radhakrishnan, A., Zu, X., \& Grover, V. (2008). A process-oriented perspective on differential business value creation by information technology: An empirical investigation. Omega, 36(6), 1105-1125.

Rai, A., Lang, S. S., \& Welker, R. B. (2002). Assessing the validity of IS success models: An empirical test and theoretical analysis. Information Systems Research, 13(1), 50-69.

Rivers, L. M., \& Dart, J. (1999). The acquisition and use of sales force automation by mid-sized manufacturers. Journal of Personal Selling and Sales Management, XIX(2), 59-73.

Saridis, G. N. (2000). Intelligent manufacturing in industrial automation. In R. L. Shell \& E. L. Hall (Eds.), Handbook of Industrial Automation (pp. 485-488). New York, US: Marcel Dekker.

Schein, E. H. (1994). The role of the CEO in the management of change: The case of information technology. In T. A. Allen \& M. S. Scott-Morton (Eds.), Information technology and the corporation of the 1990s: research studies (pp. 325). New York, US: Oxford University Press.

Seddon, P. B. (1997). A respecification and extension of the DeLone and McLean model of IS success. Information Systems Research, 8(3), 240-253.

Seddon, P. B., \& Kiew, M.-Y. (1997). A partial test and development of DeLone and McLean's model of IS success. Australasian Journal of Information Systems, 4(1), 90-109.

Stone, R. W., Good, D. J., \& Baker-Eveleth, L. (2007). The impact of information technology on individual and firm marketing performance. Behaviour \& Information Technology, 26(6), 465482.

Sun, Y., Bhattacherjee, A., \& Ma, Q. (2009). Extending technology usage to work settings: The role of perceived work compatibility in ERP implementation. Information \& Management, 46(6), 351-356.

Thompson, R., Compeau, D., \& Higgins, C. (2006). Intentions to use information technologies: An integrative model. Journal of Organizational and End User Computing, 18(3), 25-46.

Urbach, N., \& Muller, B. (2012). The updated DeLone and McLean model of information systems success. In Y. K. Dwivedi, M. R. Wade \& S. L. Schneberger (Eds.), Information Systems Theory (Vol. 1, pp. 1-18). New York, US: Springer.

Uwizeyemungu, S., \& Raymond, L. (2012). Impact of an ERP system's capabilities upon the realisation of its business value: a resource-based perspective. Information Technology and Management, 13, 69-90.

Venkatesh, V., \& Davis, F. D. (2000). A theoretical extension of the technology acceptance model: Four longitudinal field studies. Management Science, 46(2), 186-204.

Wei, Z.-G., Macwan, A. P., \& Wieringa, P. A. (1998). A quantitative measure for degree of automation and its relation to system performance and mental load. Human Factors: The Journal of the Human Factors and Ergonomics Society, 40(2), 277-295.

Wu, J.-H., \& Wang, Y.-M. (2006). Measuring KMS success: A respecification of the DeLone and McLean's model. Information \& Management, 43(6), 728-739. 
Yi, F., Purao, S., Clark, S., \& Raghuram, S. (2009). Surfacing automation criteria: A process architecture approach. Paper presented at the The 15th Americas Conference on Information Systems AMCIS, San Francisco, US.

Zuboff, S. (1985). Automate/informate: The two faces of intelligent technology. Organizational Dynamics, 14(2), 5-18. 


\section{ANNEX - INSTRUMENTS}

\section{Information Quality}

To carry out my tasks, the information system provides:

- Enough required information

- Clear information

- Data at an appropriate level of detail

- Timely information

- Sufficiently updated data

\section{System Quality}

The information system is simple to use

The information system is user-friendly

The information system is easy to use

The use of the information system is easy to understand

The descriptions of functions and commands that the information system displays are clear to me

\section{System's assistance in automating role}

To carry out my tasks, the information system to a great extent helps me to:

- Automate my tasks

- Automate my work routines

- Automate my activities

- Automate the things I have to do

- Automate my most common operations

\section{System's assistance in informating role}

To carry out my tasks, the information system to a great extent helps me to :

- Consolidate the information I require

- Analyze information

- Process information

- Summarize information

\section{Usefulness}

The information system:

Is useful to me in carrying out my tasks

Allows me to carry out my tasks more quickly

Improves the results of my tasks

Improves the quality of my tasks

\section{Systems's level of intervention}

To a great extent:

- My tasks are carried out through the information system

- The information system takes part in executing my tasks

- The "Information System" supports most of the activities of my tasks

- The activities of my tasks are included in the information system

- The execution of my tasks depends on the information system 
